\title{
Publisher Correction: Enabling "lithium-free" manufacturing of pure lithium metal solid-state batteries through in situ plating
}

\author{
Michael J. Wang (1D, Eric Carmona, Arushi Gupta, Paul Albertus (iD) \& Jeff Sakamoto (D)
}

Correction to: Nature Communications https://doi.org/10.1038/s41467-020-19004-4, published online 15 October 2020.

Figure 2a contains an error where the signal for Li stripping is missing in the published version. This is now corrected.

Published online: 10 December 2020

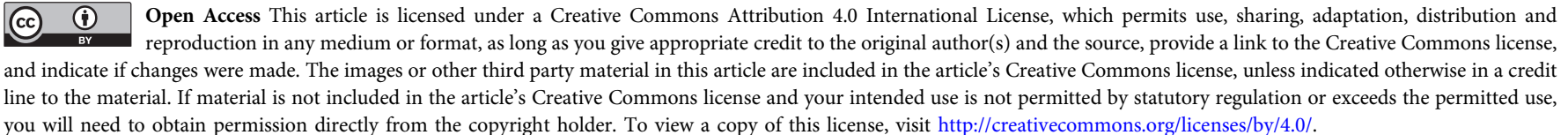
you will need to obtain permission directly from the copyright holder. To view a copy of this license, visit http://creativecommons.org/licenses/by/4.0/.

(c) The Author(s) 2020 